\title{
COOLING OF ELECTRICAL Cu CONDUCTOR WITH PVC INSULATION - ANALYTICAL, NUMERICAL AND FLUID FLOW SOLUTION
}

\author{
Vladimír Goga ${ }^{*}$ - Juraj Paulech* — Michal Váry ${ }^{*} *$
}

\begin{abstract}
This paper describes calculation of cooling process of electrical $\mathrm{Cu}$ conductor with PVC insulation. Three types of solutions were performed.Analytical solution considers free convection and radiation effect of heat transfer. Numerical solution was performed by finite element method (FEM) using software ANSYS Workbench and fluid flow solution was performed by computational fluid dynamics (CFD) analysis in software ANSYS CFX. Results from all types of solutions were compared with results of the experimental measurement.
\end{abstract}

K e y w ords: electro-thermal analysis, CFD analysis, cooling of insulated conductor, measurement, PVC insulation

\section{INTRODUCTION}

Cables with PVC based insulation blends are nowadays still one of the most applied types of cables in eastern and central Europe. Use of this material in power engineering is widespread especially due to its acceptable mechanical and electrical properties and its available price. Usually, this kind of cables is used for $400 \mathrm{~V}$ distribution lines, but also for $6 / 10 \mathrm{kV}$ voltage level, in large industrial facilities, chemical factories, traction power supplies and nuclear power plants. This applications demand very high reliability and safety. After decades of operation we experience various malfunctions of these systems caused by degradation, especially effects of thermal ageing.

Ageing is a gradual change of state and material property that usually leads to a degree of malfunction. The primal process in all cases is that the physical and chemical bonds between the atoms are repeatedly broken, reorganized and reformed in new configuration. We can say that ageing is chemical kinetics.

According to Arrhenius law, the rate of chemical reactions - the rate of degradation - increases exponentially with increasing thermodynamic temperature. It means, the lifetime of insulation decreases exponentially with increasing temperature. Empirically, taking a look to the well known law of Montsinger [1], increase of operating temperature of organic insulation material by 7 to $10^{\circ} \mathrm{C}$, causes the half reduction of the estimated lifetime.

Therefore, the maximum continuous operating performance and current loading capacity of cables and wires is important criterion in the design of cable systems (insulation materials, construction) and design of power electri- cal installation (eg deposit method). Primarily, the passing electrical current by means of Joule losses heats up the conductor and therefore its temperature and temperature of its electrical insulation system exceeds the ambient temperature. Long-term exceeding of projected operating temperatures of cable conductors causes significantly faster ageing of insulation and deterioration of its mechanical properties. Also synergic cooperation of various degradation factors have to be considered. Especially, temperature in cooperation with electric field causes significantly faster aging of power or HV cables insulation and performance interfacial aging, especially in composite material systems.

Recently, there has been rapid development of computational methods, models and simulations, which allows, as will be shown, to determine the steady state temperature of the current passing insulated conductor.

Elementary model, proposed in this paper, consists of horizontally electric copper conductor (thermal conductivity $401 \mathrm{Wm}^{-1} \mathrm{~K}^{-1}$ ) with diameter of $1.48 \mathrm{~mm}$, insulated with PVC insulation blend $0.81 \mathrm{~mm}$ thick (thermal conductivity was set to $0.14[2]$ ). The conductor carried AC current according to measurement order from 5 to 30 A RMS. Cooling of the conductor was only due to free convection and radiation effects (ambient temperature was $22^{\circ} \mathrm{C}$ ). Experimental measurements were performed to determine reference surface temperatures on the $\mathrm{Cu}$ core and on the insulation surface under steady thermalelectric state. These values were compared to the temperatures obtained from analytical calculation and numerical simulation.

Institute of Power and Applied Electrical Engineering, Slovak University of Technology, Faculty of Electrical Engineering and Information Technologies, Bratislava 812 19, Slovakia, ${ }^{*}$ Department of Applied Mechanics and Mechatronics, vladimir.goga@stuba.sk, juraj.paulech@stuba.sk ${ }^{* *}$ Department of Materials and Technologies, michal.vary@stuba.sk 


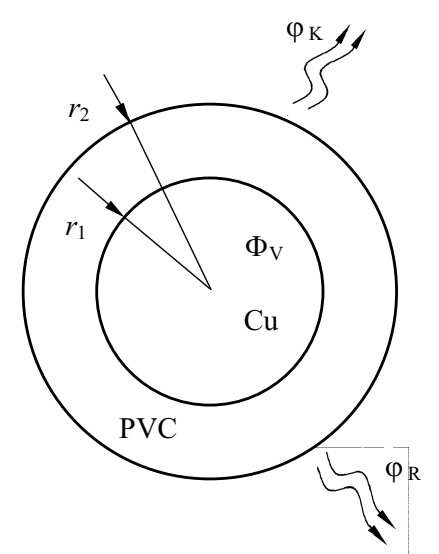

Fig. 1. Geometry and boundary conditions of insulated conductor

\section{ANALYTICAL SOLUTION}

Analytical solution outcomes from Fourier differential equation of thermal conductivity that was extended by radiation and free convection effect [3]. Convection coefficient was calculated according to criterion equations and it was set up as temperature dependent variable. Boundary conditions were Joule heat generated in conductor by electric losses, radiation and convection conditions on insulation surface. Finally, $\mathrm{Cu}$ core and PVC insulation temperature of the conductor was calculated.

\section{Nomenclature}

c specific heat $\left(\mathrm{Jkg}^{-1} \mathrm{~K}^{-1}\right)$

$c_{p}$ specific heat (constant pressure) $\left(\mathrm{Jkg}^{-1} \mathrm{~K}^{-1}\right)$

C integration constant

$g \quad$ gravity $\left(\mathrm{ms}^{-2}\right)$

Gr Grashoff number (-)

$I \quad$ electric current (A)

$L \quad$ characteristic dimension $(\mathrm{m})$

$N u$ Nusselt number (-)

$N u 0$ Nusselt number (starting value) (-)

Pr Prandtl number [-]

$r$ radius $(\mathrm{m})$

$R$ resistivity $(\Omega)$

$R a$ Rayleigh number (-)

$S$ cross-section area $\left(\mathrm{m}^{2}\right)$

$t$ surface temperature $\left({ }^{\circ} \mathrm{C}\right)$

$T$ surface temperature $(\mathrm{K})$

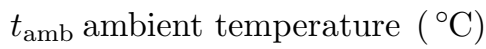

$t_{\text {amb }}$ ambient temperature $(\mathrm{K})$

$\Delta T$ difference of temperatures $(\mathrm{K})$

$V$ volume $\left(\mathrm{m}^{3}\right)$

$\alpha \quad$ convective heat transfer coefficient $\left(\mathrm{Wm}^{-2} \mathrm{~K}^{-1}\right)$

$\beta$ expansion coefficient $\left(\mathrm{K}^{-1}\right)$

$\varepsilon \quad$ emissivity $(-)$

$\lambda$ thermal conductivity $\left(\mathrm{Wm}^{-1} \mathrm{~K}^{-1}\right)$

$\mu$ dynamic viscosity $\left(\mathrm{Nsm}^{-2}\right)$

$\nu \quad$ kinematic viscosity $\left(\mathrm{m}^{2} \mathrm{~s}^{-1}\right)$ $\rho \quad$ density $\left(\mathrm{kgm}^{-3}\right)$

$\rho_{e} \quad$ electric resistivity $(\Omega \mathrm{m})$

$\sigma \quad$ Stephan-Boltzman constant

$\tau \quad$ time (s)

$$
\left(5.6704 \times 10^{-8} \mathrm{Wm}^{-2} \mathrm{~K}^{-4}\right)
$$

$\varphi \quad$ heat flux from surface $\left(\mathrm{Wm}^{-2}\right)$

$\varphi_{K}$ heat flux for convection $\left(\mathrm{Wm}^{-2}\right)$

$\varphi_{R}$ heat flux for radiation $\left(\mathrm{Wm}^{-2}\right)$

$\Phi_{V}$ generated heat $\left(\mathrm{Wm}^{-3}\right)$

General equation for heat transfer in solid materials is called Fourier-Kirchhoff law

$$
\frac{\partial t}{\partial \tau}=\frac{\lambda}{c \rho} \nabla^{2} t+\frac{\Phi_{V}}{c \rho} .
$$

For steady state temperature does not depend on time

$$
\frac{\partial t}{\partial \tau}=0
$$

Applying (2) into the (1) we obtain Poisson equation

$$
\nabla^{2} t=-\frac{\Phi_{V}}{\lambda}
$$

Our conductor that carries the electric current is horizontally arranged cylinder, so it is necessary to transform (3) into the cylindrical coordinate system

$$
\frac{\mathrm{d}^{2} t}{\mathrm{~d} r^{2}}+\frac{1}{r} \frac{\mathrm{d} t}{\mathrm{~d} r}=-\frac{\Phi_{V}}{\lambda}
$$

Solution of this second-order differential equation for unknown temperature has form

$$
t=-\frac{\Phi_{V}}{\lambda} \frac{r^{2}}{4}+C_{1} \ln (r)+C_{2} .
$$

The cross-section area of $\mathrm{Cu}$ core of conductor is solid circle therefore $r$ goes from 0 to final radius $r 1$ so term containing $\ln (r)$ has to be eliminated. We determine integration constant for $\mathrm{Cu}$ core $C_{1}=0$. Then (5) changes into (6) for surface temperature of $\mathrm{Cu}$ core

$$
t_{1}=-\frac{\Phi_{V C u}}{\lambda_{C u}} \frac{r_{1}^{2}}{4}+C_{2},
$$

where $\Phi_{V C u}$ is heat generated in $\mathrm{Cu}$ core due to Joule losses.

Heat transfer from general surface is described by Fourier law

$$
\varphi=-\lambda \operatorname{grad}(t)=-\lambda \frac{\mathrm{d} t}{\mathrm{~d} r}
$$

In our case for $\mathrm{Cu}$ core surface it is

$$
\varphi_{1}=-\lambda_{\mathrm{Cu}}\left(\frac{\mathrm{d} t}{\mathrm{~d} r}\right)_{r=r_{1}}
$$


Applying (6) into (8) we obtain heat flux from $\mathrm{Cu}$ core into the PVC insulation

$$
\varphi_{1}=\Phi_{V C u} \frac{r_{1}}{2} .
$$

According to (5) for ring shape of PVC insulation we obtain formula for temperature $\bar{t}$ of $\mathrm{PVC}$

$$
\bar{t}=-\frac{\Phi_{V P V C}}{\lambda_{P V C}} \frac{r^{2}}{4}+\bar{C}_{1} \ln (r)+\bar{C}_{2}
$$

where $P h i_{V P V C}$ is heat generated in PVC insulation which equals to zero of course. Considering this fact we get the result for derivation of equation (10)

$$
\frac{\mathrm{d} \bar{t}}{\mathrm{~d} r}=\frac{\bar{C}_{1}}{r}
$$

where $\bar{C}_{1}$ is integration constant for PVC part.

Applying (11) into the (7) we obtain heat fluxes on inner $\bar{\varphi}_{1}$ and outer $\bar{\varphi}_{2}$ surface of PVC insulation

$$
\bar{\varphi}_{1}=-\lambda_{\mathrm{PVC}} \frac{\bar{C}_{1}}{r_{1}}, \quad \bar{\varphi}_{2}=-\lambda_{\mathrm{PVC}} \frac{\bar{C}_{1}}{r_{2}} .
$$

According to our model (see Fig. 1) we consider equality between heat flux on $\mathrm{Cu}$ core surface and heat flux on inner surface of PVC insulation, that means (9) equals (12). Then we can calculate $\bar{C}_{1}$

$$
\bar{C}_{1}=-\Phi_{V C u} \frac{r_{1}^{2}}{2 \lambda_{\mathrm{PVC}}} .
$$

Applying (13) back to (12) we get heat flux for outer surface of PVC insulation

$$
\bar{\varphi}_{2}=\Phi_{V C u} \frac{r_{1}^{2}}{2 r_{2}} .
$$

This heat flow is defined by sum of convective and radiation heat flows from conductor surface. For convection it is in general

$$
\varphi_{K}=\alpha\left(t-t_{\mathrm{amb}}\right)
$$

and for radiation

$$
\varphi_{R}=\varepsilon \sigma\left(T^{4}-T_{\mathrm{amb}}^{4}\right) .
$$

Our boundary condition for surface of conductor is

$$
\bar{\varphi}_{2}=\varphi_{K}+\varphi_{R} .
$$

After some math operations using equations (14-17) we get iterative rule for calculation surface temperature of conductor (indices $[i],[i+1]$ represent iterative steps)

$$
t_{2[i]}=\frac{\Phi_{V C u}}{2 \alpha} \frac{r_{1}^{2}}{r_{2}}-\frac{T_{2[i-1]}^{4}-T_{\mathrm{amb}}^{4}}{\alpha} t_{\mathrm{amb}} .
$$

From (10) with consideration $\Phi_{V \text { PVC }}=0$ we get general equation for temperature

$$
\bar{t}=\bar{C}_{1} \ln (r)+\bar{C}_{2} .
$$

Applying (13) into (19) we get temperatures for inner and outer PVC surfaces

$$
\begin{aligned}
& \bar{t}_{1}=-\Phi_{V C u} \frac{r_{1}^{2}}{2 \lambda_{\mathrm{PVC}}} \ln \left(r_{1}\right)+\bar{C}_{2}, \\
& \bar{t}_{2}=-\Phi_{V C u} \frac{r_{1}^{2}}{2 \lambda_{\mathrm{PVC}}} \ln \left(r_{2}\right)+\bar{C}_{2} .
\end{aligned}
$$

Solving this system of equations with help of (18) we calculate integration constant $\bar{C}_{2}$ and then we can finally write equation for temperature on $\mathrm{Cu}-\mathrm{PVC}$ interface

$$
\bar{t}_{1}=-\frac{\Phi_{V C u} r_{1}^{2}}{2 \lambda_{\mathrm{PVC}}}\left[\ln \left(r_{1}\right)+\ln \left(r_{2}\right)\right]+\bar{t}_{2} .
$$

Heat generated in conductor $\Phi_{V C u}$ is calculated according to Joule heat looses in $\mathrm{Cu}$ core, so it is necessary to calculate resistance of the conductor

$$
R=\rho_{e} \frac{L}{S} .
$$

Resistivity is temperature depended variable. For cooper conductor $\left(\rho_{e 20^{\circ} \mathrm{C}}=1.69 \times 10^{-8} \Omega \mathrm{m}[4]\right)$ we obtained temperature dependency in this form $[4,8]$

$$
\rho_{e}=7.2875 \times 10^{-11} t+1.5483 \times 10^{-8}(\Omega \mathrm{m}) .
$$

Then heat generated in conductor is

$$
\Phi_{V C u}=\frac{R I^{2}}{V}=\frac{\rho_{e} I^{2}}{\pi^{2} r_{1}^{4}} .
$$

Calculation of convective heat transfer coefficient is more complicated. Convective heat transfer coefficient is calculated according to empirical equation based on Nusselt number and it is temperature dependent variable

$$
\alpha=\frac{N u \lambda_{\text {air }}}{L}=f(t) .
$$

Characteristic dimension for horizontal cylinder of diameter $\mathrm{D}$ is [5]

$$
L=\pi \frac{D}{2} .
$$

Nusselt number is the ratio of convective to conductive heat transfer across the boundary and it is calculated using next equations [5]

$$
\begin{gathered}
N u_{0}=0.36 \pi, \\
N u=\left[N u_{0}^{\frac{1}{2}}+R a^{\frac{1}{6}}\left(\frac{f(P r)}{300}\right)^{\frac{1}{6}}\right]^{2}, \\
f(P r)=\left[1+\left(\frac{0.5}{P r}\right)^{\frac{9}{16}}\right]^{-\frac{16}{9}} .
\end{gathered}
$$




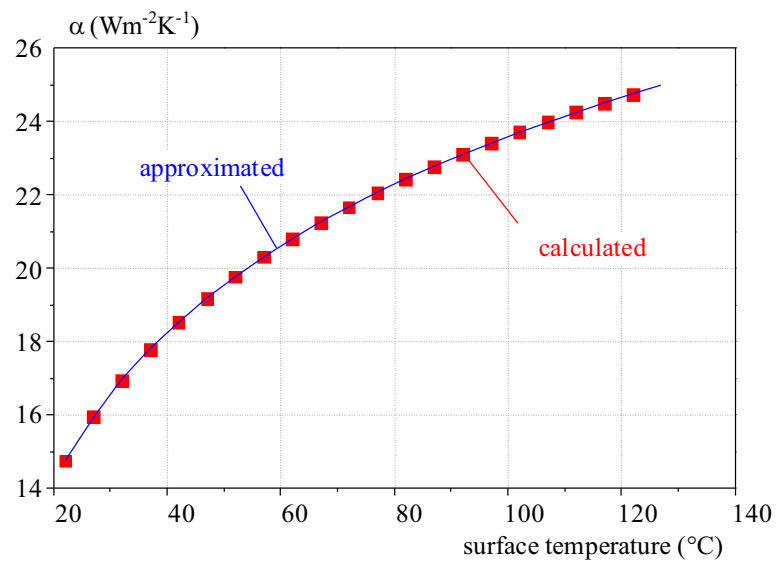

Fig. 2. Calculated and approximated values of $\alpha$

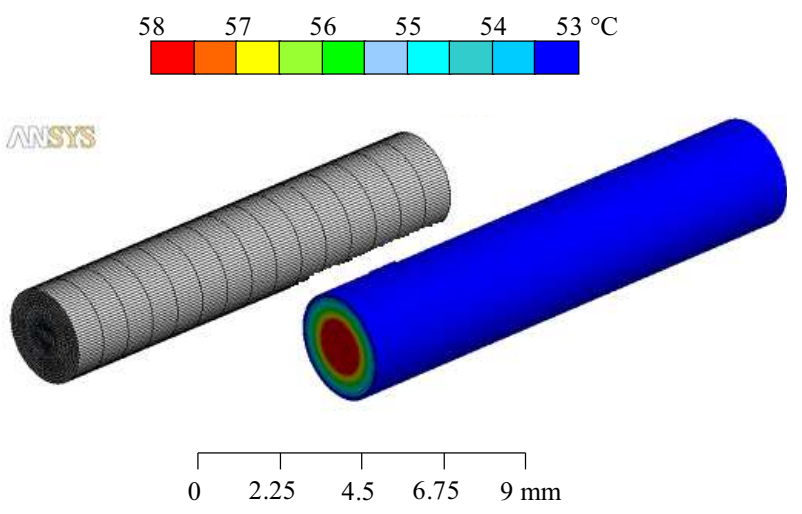

Fig. 3. Mesh (left), temperature (right) of the conductor

Table 1. Air properties for $t=20^{\circ} \mathrm{C}$

\begin{tabular}{ccccccc}
\hline$c_{\text {air }}\left(\mathrm{Jkg}^{-1} \mathrm{~K}^{-1}\right)$ & $\operatorname{Pr}(-)$ & $\beta_{\text {air }}\left(\mathrm{K}^{-1}\right)$ & $\mu_{\text {air }}\left(\mathrm{Nsm}^{-2}\right)$ & $\nu_{\text {air }}\left(\mathrm{m}^{2} \mathrm{~s}^{-1}\right)$ & $\lambda_{\text {air }}\left(\mathrm{Wm}^{-1} \mathrm{~K}^{-1}\right)$ & $\rho_{\text {air }}\left(\mathrm{kgm}^{-3}\right)$ \\
$1.007 \times 10^{3}$ & 0.7083 & $3.43 \times 10^{-3}$ & $1.811 \times 10^{-5}$ & $1.527 \times 10^{-5}$ & $2.589 \times 10^{-2}$ & 1.186 \\
\hline
\end{tabular}

Table 2. Surface temperatures — analytical solution

\begin{tabular}{ccc}
\hline$I(\mathrm{~A})$ & $t_{\text {analytical Cu}}\left({ }^{\circ} \mathrm{C}\right)$ & $t_{\text {analytical PVC }}\left({ }^{\circ} \mathrm{C}\right)$ \\
\hline 5 & 23.58 & 23.37 \\
10 & 28.16 & 27.31 \\
15 & 35.52 & 33.53 \\
20 & 45.62 & 41.94 \\
25 & 58.67 & 52.64 \\
30 & 75.09 & 65.87 \\
\hline
\end{tabular}

The Rayleigh number is defined as the product of the Grashof number, which describes the relationship between buoyancy and viscosity within a fluid, and the Prandtl number, which describes the relationship between momentum diffusivity and thermal diffusivity. Hence, the Rayleigh number itself may also be viewed as the ratio of buoyancy and viscosity forces times the ratio of momentum and thermal diffusivities. For free convection around horizontally arranged cylindrical conductor these equations are

$$
R a=G r \operatorname{Pr}, G r=\frac{g \beta_{a i r} \Delta T L^{3}}{\nu_{a i r}^{2}}, \operatorname{Pr}=\frac{c_{p a i r} \mu_{a i r}}{\lambda_{a i r}} .
$$

Air kinematic viscosity is based on dynamic viscosity and density of air and all these material properties including air thermal conductivity are temperature dependent variables

$$
\nu_{a i r}=\frac{\mu_{a i r}}{\rho_{a i r}} .
$$

Air properties for $t=20^{\circ} \mathrm{C}$ are presented in Tab. 1 .

Temperature dependencies for these air properties were calculated for specified temperature range $22-127^{\circ} \mathrm{C}$. According to (25) convective heat transfer coefficient was calculated as temperature dependent variable. Approximation function for $\alpha_{\text {approx }}$ was obtained as (see Fig. 2)

$$
\alpha_{\text {approx }}=5.84 \ln (t)-3.305 \text {. }
$$

Table 3. Surface temperatures — numerical solution

\begin{tabular}{ccc}
\hline$I(\mathrm{~A})$ & $t_{\mathrm{E}-\mathrm{T} \mathrm{Cu}}\left({ }^{\circ} \mathrm{C}\right)$ & $t_{\mathrm{E}-\mathrm{T} \mathrm{PVC}}\left({ }^{\circ} \mathrm{C}\right)$ \\
\hline 5 & 23.56 & 23.35 \\
10 & 28.15 & 27.30 \\
15 & 35.55 & 33.56 \\
20 & 45.66 & 41.98 \\
25 & 58.75 & 52.70 \\
30 & 75.19 & 65.96 \\
\hline
\end{tabular}

Next unknown parameter in (18), that describes conductor surface temperature, is coefficient of emissivity $\varepsilon$. For our case the value of emissivity was chosen in accordance to [6] for yellow-green PVC insulation $\varepsilon=0.62$. Finally boundary conditions for our model are:

- electric current $I$,

- free convection defined with convective heat transfer coefficient $\alpha=\alpha(t)$ and ambient temperature $t_{\mathrm{amb}}=$ $22{ }^{\circ} \mathrm{C}$,

- radiation effect with emissivity $\varepsilon=0.62$,

- considered infinite length of conductor.

Now it is possible to calculate iterative rule (18) for conductor surface temperature and equation (21) for $\mathrm{Cu}$ core surface temperature for chosen range of electric currents. These calculations were performed in software Mathematica [7]. Results are in Tab. 2.

\section{NUMERICAL SOLUTION - ELECTRO-THERMAL ANALYSIS}

To obtain numerical solution ANSYS Workbench program [8] was used, where steady-state electro-thermal (abbr. E-T) simulation was performed. The model and all boundary conditions were created according to the analytical solution. Material properties of $\mathrm{Cu}$ core and 


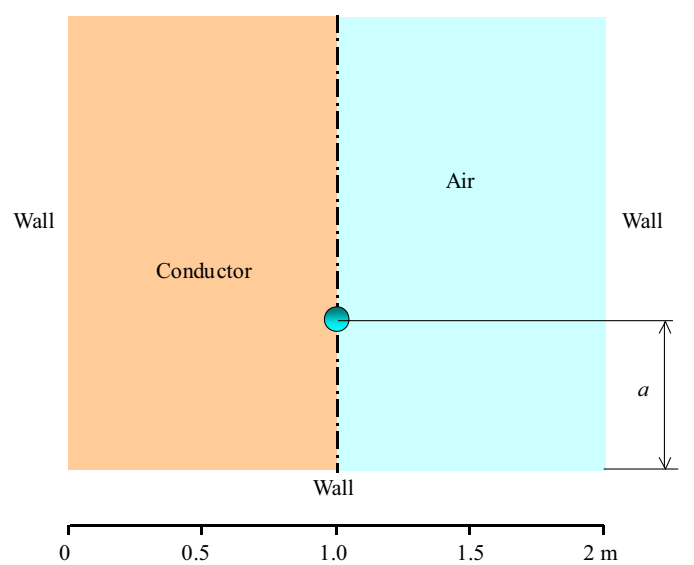

Fig. 4. Conductor position in the air area

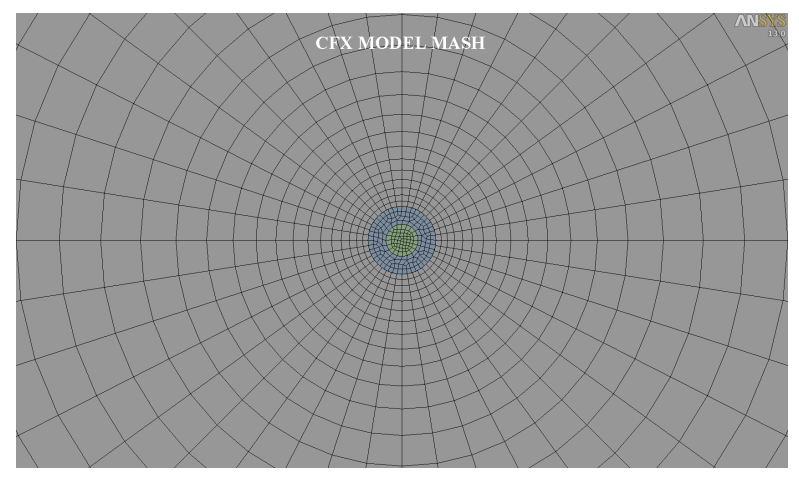

Fig. 5. Mesh for CFX model

convective heat transfer coefficient were set as temperature dependent variables. Material properties of PVC were considered as temperature independent. Mesh of finite electro-thermal 3D elements was created in the same software, see Fig. 3. Surface temperatures of the $\mathrm{Cu}$ core and PVC insulation were obtained directly from the software, see Fig. 3. Results from this numerical solution are in Tab. 3.

\section{FLUID FLOW SOLUTION - CFX ANALYSIS}

Fluid flow analysis was performed in software ANSYS CFX [9]. Geometry for the model:

- air area around the conductor: block with dimensions $2000 \times 3000 \times 1 \mathrm{~mm}$ (this area represents room with the conductor, thickness $1 \mathrm{~mm}$ is due to symmetry boundary condition mentioned below),

- conductor geometry: $\mathrm{Cu}$ core is represented by cylinder with diameter $1.48 \mathrm{~mm}$ and PVC insulation is ring with inner diameter $1.48 \mathrm{~mm}$ and outer diameter $3.1 \mathrm{~mm}$, both have length $1 \mathrm{~mm}$,

- position of conductor: $a=1100 \mathrm{~mm}$, see Fig. 4 .

We need to create mesh of volume elements in the air area. The mesh around the conductor surface and walls must be very fine (called inflation) because of near-wall boundary flow has to be modeled, see Fig. 5. Meshes for solid parts were also created. Final number of elements was 188446 .

Boundaries of the air area were set as adiabatic walls. Air properties were chosen according to ANSYS CFX material library. The model was set up to solve free convection.

The body of conductor itself was modeled also. Joule heat generation was considered in $\mathrm{Cu}$ core. The reason why the thickness of the model is only $1 \mathrm{~mm}$ is that there are symmetry conditions on the front and back surface of the model. That means the model itself represents infinite region in this direction (infinite length of the conductor).

The simulation was calculated as steady-state analysis using cluster computer $16 \times 4.4 \mathrm{GHz}$ cores, $64 \mathrm{~GB}$ of RAM. Iterative solution took approximately 10 hours for every load step (number of iterations approx. 15000).

Cooling of conductor by free convection is shown in Fig. 6. Figure 7 shows inconstant values of convective heat transfer coefficient (in previous solutions it was considered as constant value for given temperature) on conductor surface calculated in CFX for loading current $25 \mathrm{~A}$. Final surface temperature of the conductor was obtained as average temperature on the conductor surface, see Fig. 8. But this average temperature is not constant value during fictive iteration time (real behavior of air flow around conductor is oscillating transient stream, called von Kármán stream $[10,11])$, therefore the average temperature was obtained according to chosen number of iterations at the end of simulation, see Fig. 9. Final results of surface temperatures are in Tab. 4.

Table 4. Surface temperatures — fluid flow solution

\begin{tabular}{ccccc}
\hline $\begin{array}{c}I \\
(\mathrm{~A})\end{array}$ & $\begin{array}{c}t_{\mathrm{CFX} \mathrm{Cu}}\left({ }^{\circ} \mathrm{C}\right) \\
5\end{array}$ & $\begin{array}{c}t_{\mathrm{CFX} \mathrm{PVC} \mathrm{min}} \\
\left({ }^{\circ} \mathrm{C}\right)\end{array}$ & $\begin{array}{c}t_{\mathrm{CFX} \text { PVC max }} \\
\left({ }^{\circ} \mathrm{C}\right)\end{array}$ & $\begin{array}{c}t_{\mathrm{CFX} \mathrm{PVC} \text { ave }} \\
\left({ }^{\circ} \mathrm{C}\right)\end{array}$ \\
\hline 10 & 24.18 & 23.90 & 24.01 & 23.96 \\
15 & 37.44 & 28.36 & 28.69 & 28.52 \\
20 & 48.77 & 44.59 & 35.87 & 35.47 \\
25 & 63.34 & 56.38 & 58.86 & 45.04 \\
30 & 81.06 & 70.60 & 74.01 & 57.28 \\
\hline
\end{tabular}

Table 5. Surface temperatures - measurement

\begin{tabular}{ccc}
\hline $\begin{array}{c}I \\
(\mathrm{~A})\end{array}$ & $\begin{array}{c}t_{\text {measure Cu }} \\
\left({ }^{\circ} \mathrm{C}\right)\end{array}$ & $\begin{array}{c}t_{\text {measure PVC }} \\
\left({ }^{\circ} \mathrm{C}\right)\end{array}$ \\
\hline 5 & 23.9 & 23.5 \\
10 & 29.3 & 28.5 \\
15 & 37.4 & 36.1 \\
20 & 47.5 & 45.8 \\
25 & 62.6 & 60.0 \\
30 & 80.1 & 75.2 \\
\hline
\end{tabular}



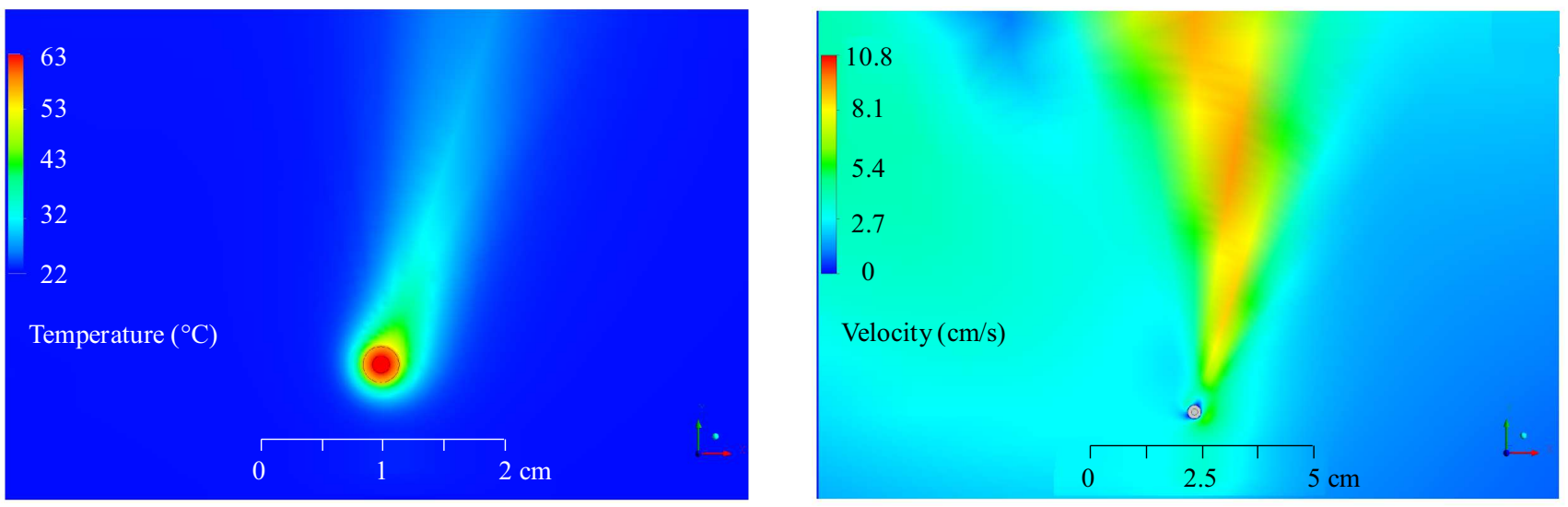

Fig. 6. Air temperature around conductor (left) and air velocity (right) - ANSYS CFX

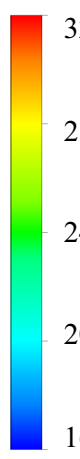

32

28

24

20

$16 \mathrm{Wm}^{-2} \mathrm{~K}^{-1}$

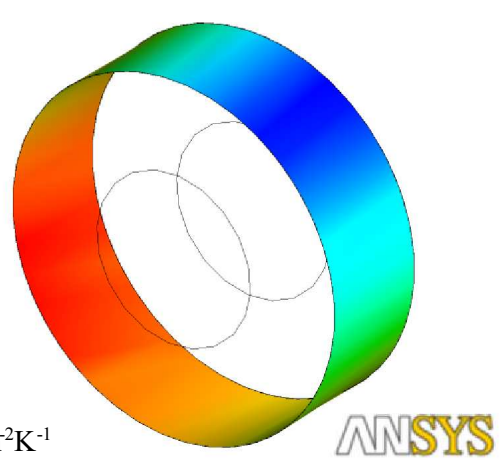

aNSIS

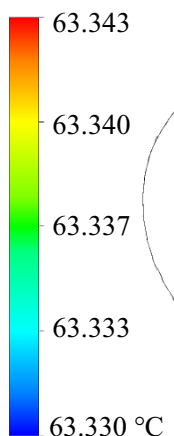

$63.330^{\circ} \mathrm{C}$

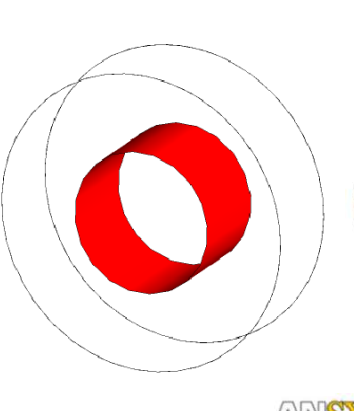

ANSYIS
58.603

58.05

57.49

56.94

$56.38^{\circ} \mathrm{C}$
Fig. 7. Convective heat transfer coefficient (loading current $25 \mathrm{~A}$ )

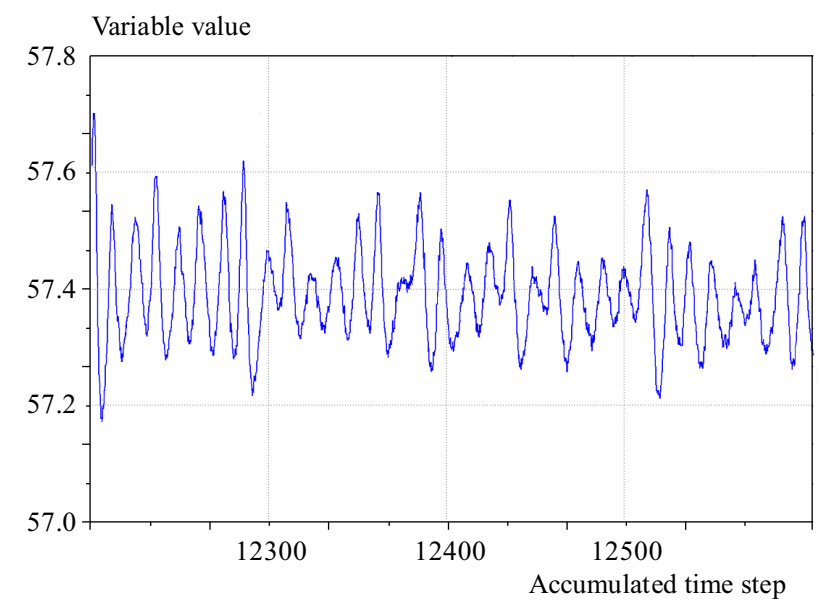

Fig. 9. Temperature changes on conductor surface during iterative process

\section{EXPERIMENTAL MESUREMENT}

The experimental results proposed in this paper were achieved by loading characteristic measurements for horizontal $\mathrm{Cu}$ conductor, diameter $1.48 \mathrm{~mm}$, with PVC blend
Fig. 8. Temperature (loading current $25 \mathrm{~A}$ ) - surface of $\mathrm{Cu}$ core (left) and outer surface of PVC insulation (right)

insulation, $0.81 \mathrm{~mm}$ thick. Current in the measurement circuit $(5,10,15,20,25$ and 30 Amps AC) was regulated by autotransformer (AT) and current transformer (PT) (see Fig. 10 for connection details) and measured by analog ammeter (A) (precision $0.5 \%$ ). Conductor surface temperatures under insulation and on the PVC insulation surface were measured by K-type thermocouple and real time logged into computer by Fluke 289 multimeter (MT) and support logging software Fluke View Forms (PC), see Fig. 11. Time logging interval was set to 5 seconds. Temperature measurement precision was $0.5 \%$. Ambient temperature during measurement was $22^{\circ} \mathrm{C}$. Results from measurement are in Tab. 5.

\section{DISCUSSION}

Figures 12 and 13 show calculated and measured surface temperatures of conductor in graphic form. In Tabs. 6 and 7 there are differences of temperature for the individual solutions in comparison to experimental results. There are approximately the same results of temperatures for analytical and numerical (electro-thermal) solution for $\mathrm{Cu}$ core and PVC insulation. But these results are much 
Table 6. Differences of $\mathrm{Cu}$ core surface temperatures for the individual solutions in comparison with experimental results

\begin{tabular}{ccccc}
\hline$I$ & $\begin{array}{c}t_{\text {mesuare }} \\
(\mathrm{A})\end{array}$ & $\begin{array}{c}\left.\Delta t_{\text {analytical }} \mathrm{C}\right) \\
(\%)\end{array}$ & $\begin{array}{c}\Delta t_{\mathrm{E}-\mathrm{T}} \\
(\%)\end{array}$ & $\begin{array}{c}\Delta t_{\mathrm{CFX}} \\
(\%)\end{array}$ \\
\hline 5 & 23.9 & 1.34 & 1.42 & -1.17 \\
10 & 29.3 & 3.89 & 3.92 & -0.34 \\
15 & 37.4 & 5.02 & 4.95 & -0.11 \\
20 & 47.5 & 3.96 & 3.87 & -2.67 \\
25 & 62.6 & 6.28 & 6.15 & -1.18 \\
30 & 80.1 & 6.25 & 6.13 & -1.20 \\
\hline
\end{tabular}

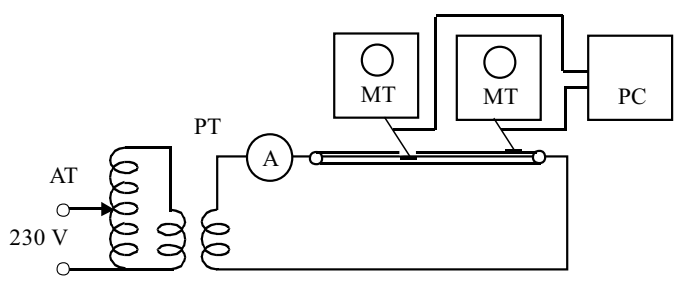

Fig. 10. Schematic illustration of the experimental setup

more different in comparison with measurement or results of fluid flow solution.

Analytical and numerical solutions consider identical and constant convection heat transfer around the conductor what is not correct in physical point of view. Air around the conductor is heated and therefore it flows around conductor with different velocities (see Fig. 6) and causes different heat drain around the conductor surface (inconstant convective heat transfer coefficient, see Fig. 7). CFX analysis considers effect of air flow and its results correspond much better with experimental measurement. CFX disadvantage is hardware- and timeintensiveness and therefore the results from other two solutions can be acceptable for such simple problems like this particular problem is. But CFX great advantage is its automatic calculation of convective heat transfer coefficient, which calculation is problematic if the solid geometry is complicated.

\section{CONCLUSION}

In this paper the complex analysis of loaded horizontal electrical $\mathrm{Cu}$ conductor with PVC insulation cooling process was performed. Results of analytical solution, considering free convection and radiation effect of heat transfer, numerical solution by finite element method (FEM) and fluid flow solution by computational fluid dynamics (CFD) analysis were compared with experimental data.

The best compliance of results was achieved by the robust solution is CFD analysis, because there is no need to build analytical equations and calculate convective
Table 7. Differences of PVC surface temperatures for the individual solutions in comparison with experimental results

\begin{tabular}{ccccc}
\hline$I$ & $\begin{array}{c}t_{\text {mesuare }} \\
(\mathrm{A})\end{array}$ & $\begin{array}{c}\Delta t_{\text {analytical }} \\
(\%)\end{array}$ & $\begin{array}{c}\Delta t_{\mathrm{E}-\mathrm{T}} \\
(\%)\end{array}$ & $\begin{array}{c}\Delta t_{\mathrm{CFX} \text { ave }} \\
(\%)\end{array}$ \\
\hline 5 & 23.5 & 0.55 & 0.64 & -1.96 \\
10 & 28.5 & 4.18 & 4.21 & -0.07 \\
15 & 36.1 & 7.12 & 7.04 & 1.75 \\
20 & 45.8 & 8.43 & 8.34 & 1.66 \\
25 & 60.0 & 12.27 & 12.17 & 4.53 \\
30 & 75.2 & 12.41 & 12.29 & 4.45 \\
\hline
\end{tabular}

heat transfer coefficient. Solving process is relatively more hardware- and time-intensive than ANSYS Workbench solution, though.

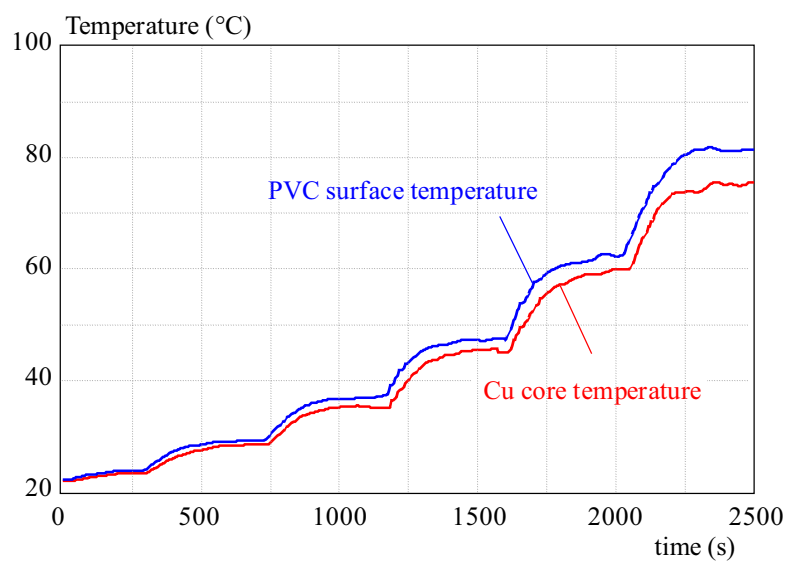

Fig. 11. Time evolution of conductor temperature and insulation surface temperature (loading currents: 5, 10, 15, 20, 25, $30 \mathrm{~A}$

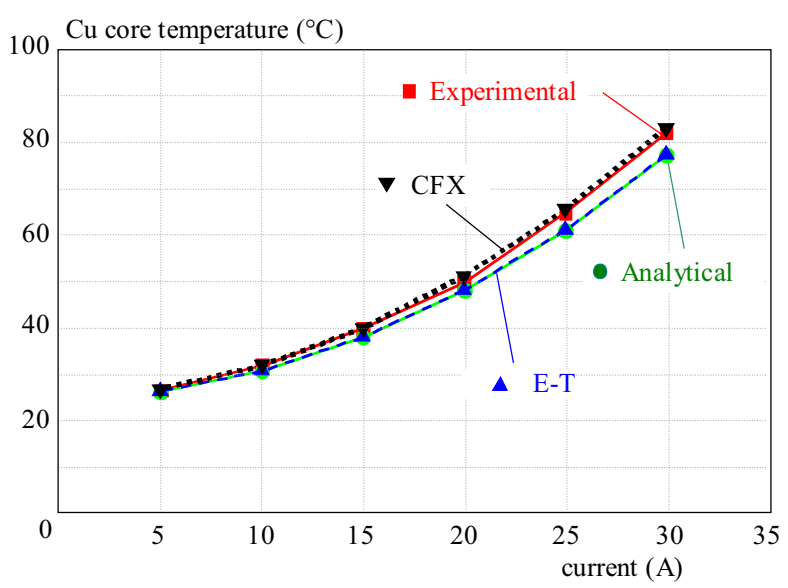

Fig. 12. Graph of $\mathrm{Cu}$ core surface temperatures

The advantages of this approach are in the possibility of optimization of given issue. Currently, this approach, based on diagnostic measurement input data, can be used for thermal field simulations in cables and electric machines, which results can be used for faulty states and spots evaluation and life time predictions.

It is important to mention that this computational approach may also have limited application and relevance of 


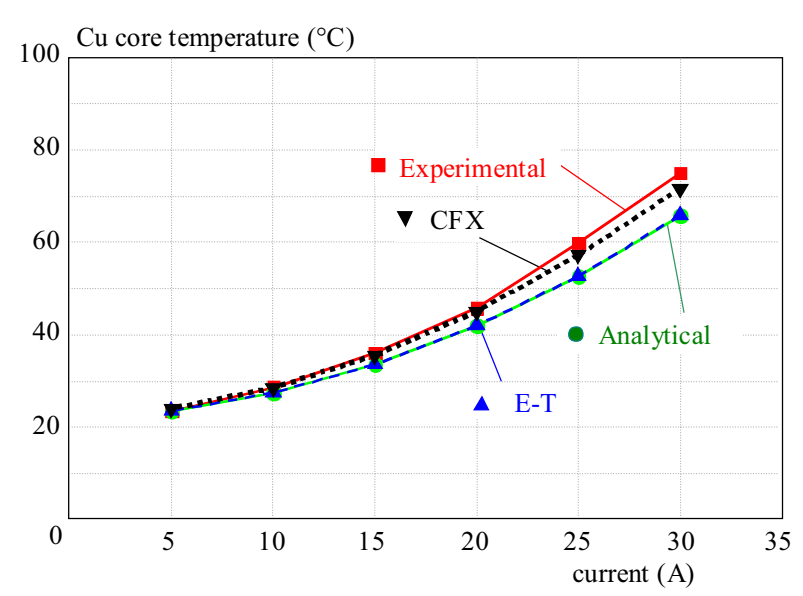

Fig. 13. Graph of PVC surface temperatures

results in very complex cases (cable with multiple loaded cores, vertical cable /wire) or in cases when the values of constants and their temperature dependencies for calculation of heat transfer are not given or known (underground cables, cables with so called airbag or similar). In these cases the loading capacitance could be better determined by experimental approach.

\section{Acknowledgements}

This contribution is the result of the project Increase of Power Safety of the Slovak Republic, ITMS 26220220077 supported by the Research \& Development Operational Programme funded by the ERDF. This work was supported by Grant Agency KEGA, grant No. 015STU4/2012 and grant VEGA 1/0534/12.

\section{REFERENCES}

[1] MONTSINGER, V. M. : Loading Transformer by Temperature, AIEE Transactions 49 (1930), 776-792.

[2] MATBASE a leap forward in material data, available online from http://www.matbase.com/material/polymers/commodity/ soft-pvc/properties, accessed 2012-8-31.

[3] KALOUSEK, M.-HUČKO, B. : Heat transfer (Prenos tepla), Vydavatestvo STU, Bratislava, 1996. (in Slovak)

[4] MAtUlA, R. A.: Electrical Rezistivity of Copper, Gold, Palladium and Silver, J. Phys. Chem. Ref. Data 8 No. 4 (1979), $1147-1298$.
[5] BennetT, C. O.: Momentum, Heat and Mass Transfer, McGraw-Hill, 1962.

[6] ZHU, S.-DELTOUR, J.-WANG, S. : Modeling the Thermal Characteristics of Greenhouse Pond Systems, Aquacultural Engineering 18 (1998), 201-217.

[7] Wolfram Mathematica 8 (2011).

[8] ANSYS, Theory Manual for Workbench, 2011.

[9] ANSYS CFX, Theory Manual, 2011.

[10] MAAS, W. J. P. M.-RINDT, C. C. M.-STEENHOVEN, A. A. : The Influence of Heat on the 3D-Transition of the von Krmn Vortex Street, International Journal of Heat and Mass Transfer 46 No. 16 (July 2003), 3069-3081.

[11] GODARD, G.-WEISS, F.-GONZALEZ, M.-PARANTHOËN, P. : Heat Transfer from a Line Source Located in the Periodic Laminar Near Wake of a Circular Cylinder, Experimental Thermal and Fluid Science 29 No. 8 (Sep 2005), 947-956.

Received 6 August 2012

Vladimír Goga, born in Štúrovo (Slovakia) in 1981, graduated at the Slovak University of Technology in Bratislava, Faculty of Mechanical Engineering in 2004. He received PhD degree in applied mechanics from the Slovak University of Technology in Bratislava, in 2009. He is assistant professor at Institute of Power and Applied Electrical Engineering, Department of Applied Mechanics and Mechatronics, at his Alma Mater. His research interests are: dynamics of mechanical systems, structural mechanics, material testing, computational mechanics and mechatronics.

Juraj Paulech, born in Trnava (Slovakia) in 1984, graduated the Slovak University of Technology in Bratislava, Faculty of Electrical Engineering and Information Technologies in 2009. He is PhD student at Institute of Power and Applied Electrical Engineering, Department of Applied Mechanics and Mechatronics, Slovak University of Technology in Bratislava, Slovakia. His research interests include: thermal-fluid flow dynamics, FEM elements for FGM materials, computer simulations for renewable energy sources.

Michal Váry, born in Nitra, Slovakia in 1979. He graduated from the Slovak University of Technology in Bratislava, Faculty of Electrical Engineering and Information Technologies in 2004. He received the $\mathrm{PhD}$ degree in electrical engineering, materials and technologies, from the Slovak University of Technology in Bratislava, in 2009 and at present is the assistant professor at Institute of Power and Applied Electrical Engineering, Department of Materials and Technologies, of his Alma Mater. His research interests include: cable insulation systems aging, polarization processes in dielectric materials, monitoring of photovoltaic systems performance, aging of photovoltaic systems encapsulation materials. 